\title{
Üstün/Özel Yetenekli Öğrencilerle Yapılan Okul Dışı STEM Eğitiminin Değerlendirilmesi ${ }^{1}$
}

\section{Evaluation of Gifted/Talented Students' Out-of-School STEM Education}

\section{Aybike ÖZÇELİK², Devrim AKGÜNDÜZ ${ }^{3}$}

\begin{abstract}
Öz: STEM (Science, Technology, Engineering \& Mathematics), fen bilimleri ve matematik gibi temel bilimlerin, mühendislik ve teknolojinin tasarım ve uygulamaları ile entegre edilmesini sağlayan bir yaklaşımdır. Literatür incelendiğinde STEM eğitiminin üstün/özel yeteneklilere uygulanması ile ilgili araştırmaların yetersiz olduğu görülmüştür. Bundan dolayı bu araştırma, üstün/özel yetenekli öğrenciler için yapılan STEM eğitimi ile öğrencilerin elde ettikleri kazanımları değerlendirmek amacıyla yapılmıştır. Araştırmada nitel araştırma modellerinden durum çalışması kullanılmıştır. Araştırma, daha önceden STEM eğitimi almamış ve üstün/özel yetenekli tanısı konulmuş 12 erkek ve $13 \mathrm{k} 1 \mathrm{z}$ olmak üzere toplam 25 ögrencinin katılımıyla 2 haftada 32 saat olarak gerçekleştirilmiştir. Veri toplama aracı olarak Aktivite Değerlendirme Formları kullanılmıştır. Aktivite değerlendirme formunda öğrencilerin neler öğrendiği, hangi becerileri elde ettiği, etkinlikten öğrendiklerini nasıl kullanacağ 1 vb. sorular yöneltilmiştir. Yapılan her aktivite için STEM eğitimine yönelik ders planı oluşturulmuş, uygulamada mühendislik tasarım süreci izlenmiş ve aktivite sonrasında öğrencilerin aktivite formlarını doldurmaları sağlanmıştır. Elde edilen nitel veriler betimsel analiz tekniği ile değerlendirilmiştir. Sonuç olarak üstün/özel yetenekli öğrenciler için yapılan STEM eğitiminin öğrencilerin fen ve matematik kazanımları ile yaratıcılık, eleştirel düşünme, işbirliği yapma ve iletişim kurma gibi 21. Yüzyıl becerileri elde etmesini sağladığı tespit edilmiştir.
\end{abstract}

Anahtar sözcükler: STEM eğitimi, Üstün/Özel Yetenekliler, Okul Dışı Öğrenme, Fen Ĕ̆itimi

\begin{abstract}
STEM is an approach, which provides to integrate fundamental science and mathematics with design and applications of engineering and technology. When the literature is examined, it has been found that researches on STEM education to gifted/talented students is inadequate. Therefore, this study has been carried out in order to examine the benefits earned by gifted/talented students based on STEM education. In the study, case study model were used from qualitative research models. STEM education applications have been performed a total of 32 hours in 2 weeks. The participants consisted of 25 students ( 12 boys and 13 girls) diagnosed as "gifted/talented". They did not participate in any STEM education before. Activity Assessment Forms were used for data collection instrument. In these
\end{abstract}

$1 \mathrm{Bu}$ çalışma 12. Ulusal Fen Bilimleri ve Matematik Kongresinde sözlü bildiri olarak sunulmuştur. 2 Yüksek Lisans Öğrencisi, Mektebim Okulları, email: ozcelikaybike@gmail.com

3 Yrd. Doç. Dr. İstanbul Aydın Üniversitesi, email: devrimakguduz@gmail.com 
forms, various questions addressed to students, which likely to ask learnings and benefits by students' point of view. During the application of each STEM activity, a lesson plan for STEM education was prepared, engineering design cycle was followed and students made to complete the Activity Assessment Forms. Obtained qualitative data evaluated by using descriptive analysis technique. Consequently, it has been determined that STEM education applications improves the skills, in particular, creativity, critical thinking, collaboration and communication. It also enhances educational attainments in science and math.

Keywords: STEM Education, Gifted and Talented Students, Outdoor Learning, Science Education)

\section{GIRISŞ}

İçinde bulunduğumuz çağda öğrencilerin 21. Yüzy1l becerileri denilen yaratıcılık, eleştirel düşünme, iletişim kurma, işbirliği yapma, problem çözme ve teknoloji okuryazarı olma gibi becerilere sahip olması (P21, 2016), ürün odaklı çalışmalar yapması için yenilikçi yaklaşımlara ihtiyaç bulunmaktadır. 21. Yüzyılda bu yeni yaklaşımların en önemlisi STEM eğitim yaklaşımıdır (Science-Fen, Technology-Teknoloji, Engineering-Mühendislik ve Mathematics-Matematik). Amerika Birleşik Devletleri (ABD) kökenli bir kavram olan STEM fen ve matematiğin bilgilerinin, mühendislik ve teknolojinin pratik ve uygulamaları ile bütünleştirilmesi anlamına gelmektedir (Akgündüz ve diğerleri, 2015a, 2015b). Doğru uygulanan bir STEM eğitimi öğrencilerin araç-gereçlerin çalışma prensiplerini anlama ve teknolojiyi etkin bir biçimde kullanma gibi özelliklerini geliştirir (Bybee, 2010). Ayrıca STEM alanlarına yönelik öğrencilerin bilgi düzeylerinin gelişmiş olması öğrencilerin bu alanlara yönelik ilgi ve öğrenmelerini geliştirmekle beraber gelecekte yapacakları meslek tercihleri açısından önemlidir (Becker ve Park, 2011; Akgündüz ve diğerleri, 2015a; Haciömeroğlu ve Kılıç, 2016).

STEM ABD'de bir devlet eğitim politikası haline gelmiştir. ABD başkanı geleceğin liderliğinin öğrencilerin özellikle STEM alanında nasıl eğitileceğine bağlı olduğunu söyleyerek STEM'in çok önemli bir konu olduğunu belirtmektedir (Akgündüz ve diğerleri, 2015a). ABD'de STEM eğitiminin müfredatta yer alması üzerine çalışmalar sürmektedir. Next Generation Science Standarts denilen yeni nesil fen eğitimi standartları STEM eğitimini de bünyesine almaktadır (Achieve, 2012). Ancak bu müfredatın başarıyla uygulanmasında sıkıntılar yaşanmaktadır (Akgündüz ve diğerleri, 2015). STEM eğitimi bu yüzden daha çok okul dışı çalışmalarla yapılmaktadır. Türkiye'de de hem müfredat içinde hem de okul dış1 STEM eğitimi çalışmaları mevcuttur (Baran, Bilici, Mesutoğlu ve Ocak, 2015; Gencer, 2015; Şahin, Ayar ve Adıgüzel, 2014; Yamak, Bulut ve Dündar, 2014; EGEÇEM, 2017; STEM OKULU, 2017). Bunlardan STEM eğitimini ön plana çıkarmamakla birlikte mühendislik üzerine kurgulanan çalışmalar da mevcuttur (Çavaş, Bulut, Holbrook, \& Rannikmae, 2013).

İçinde bulunduğumuz yüzyılda öğrencilerin arasında gerek fizyolojik gerekse psikolojik farklılıklar olduğu ve onlara eğitimlerinin bu farklılıkları göz önüne alarak verilmesi gerektiği konusunda birçok çalışmalar yapılmıştır ve yapılmaya devam edilmektedir. Akranlarına göre bir ve/veya birden fazla alanda ciddi oranda sivrilmiş bir yeteneğe sahip çocuklar "üstün yetenekli çocuklar "olarak adlandırılmaktadır. Üstün/özel yetenekliler, normal eğitim programları ile sağlanamayan geniş kapsamlı 
eğitim olanaklarına ve hizmetlerine gereksinim duyan, bütün insanlarda bulunan özelliklerin farklı dağılım, sıklık, zamanlama ve kompozisyonlarının farklılık gösterdiği bireylerdir. (Akarsu, 2001; Gökdere ve Çepni, 2004). İhtiyaçları ve kişilik özellikleri yönünden akranlarından farklı olan üstün/özel yetenekli kişilerin normal müfredat dışında daha farklı eğitim uygulamalarına ihtiyaçları bulunmaktadır (Bakioğlu ve Levent, 2013).

Üstün zekâlı ve yetenekli çocuklar için en etkili sınıflar farklılaştırılmış uygulamaların kullanıldığı sınıflardır. Farklılaştırma, akademik olarak her çocuğun ilgi ve hazır bulunuşluklarına cevap verebilecek içerik, süreç ve ürün içeren çeşitli etkinlikler kullanmaktır (Tomlinson, 2000). STEM eğitimi bu tür öğrencilere bütünleşik ve farklılaştırılmış öğrenme firsatı yaratabilir. Çünkü STEM eğitimi yapılırken onların yeteneklerini ortaya çıkaran ve çok boyutlu düşünmelerine firsat veren etkinlikler gerçekleştirilebilmektedir.

Üstün/özel yetenekli öğrenciler, nesneler ve doğal çevreleri hakkında sahip oldukları güçlü merak duygularını ve hayal güçlerini harekete geçirdiği için fene doğal bir ilgileri bulunmaktadır (Smutny ve Von Fremd, 2004). VanTassel-Baska ve Stambaugh (2006) üstün/özel yetenekliler için uygulanacak fen eğitiminin disiplinlerarası etkileşimleri geliştirmek ve gerçek yaşam problemlerini araştırma becerisini geliștirme bileșenlerini içermesi gerektiğini belirtmişlerdir. Bu durumda fen eğitiminin diğer derslerle ve özellikle matematikle entegre edilmesi gerektiğine işaret etmektedir. Fen ve matematik entegrasyonunun bulunduğu etkinlikler yapılması onların akademik bilgileri daha iyi öğrenmelerine firsat sağlayacaktır. Nitekim TylerWood (2000) yllında fen ve matematikte yüksek yeteneğe sahip öğrenciler için uygulamalı bir ortamda fen ve matematik öğretimi yaptı̆̆ $\mathrm{Ga}$-GEMS adlı projesinde (Georgia's Project for Gifted Education in Math and Science- Üstün Zekâlı ve Yetenekli Öğrencilere Fen ve Matematik Öğretiminde Georgia Projesi) deneysel bir çalışma gerçekleștirmiş ve Amerikan Kolej Testi'nin fen ve matematik alt boyutlarında deney grubunun daha yüksek puanlara eriştiğini gözlemlemiştir. Kim, Roh ve Cho (2016) üstün zekâlı öğrencilerin bütünleşik bir öğretim ile matematik ve fen kavramlarını ayrı düşünmediklerini ve onların doğru çözüm süreçleri tasarladıklarını ayrıca problemleri yaratıcı bir şekilde çözdüklerini öne sürmektedir. Üstün/özel yetenekli öğrencilerin ilgi ve hazır bulunuşluklarına yönelik olarak bütünleştirilmiş fen ve matematik eğitimi almaları için STEM eğitiminin uygulanması ve onların STEM alanındaki mesleklere ilgilerinin tespit edilip erken yaşlarda yönlendirilmesi gerekmektedir. STEM eğitimi henüz yeni bir yaklaşım olarak karşımıza çıkarken, üstün/özel yetenekliler ile ilgili yapılan araştırmalar son derece sınırlıdır. Normal yeteneklilerde olduğu kadar üstün/özel yetenekliler için yapılacak STEM eğitiminin çok boyutlu olarak değerlendirilmesine ihtiyaç bulunmaktadır.

$\mathrm{Bu}$ araştırma, üstün/özel yetenekli öğrenciler için yapılan okul dışı STEM eğitimi ile öğrencilerin elde ettikleri kazanımları ve becerileri değerlendirmek amacıyla yapılmıştır.

\section{YÖNTEM}

\subsection{Araştırma Modeli}

$\mathrm{Bu}$ araştırmada nitel araştırma modellerinden durum çalışması kullanılmıştır. Durum çalışması, araştırmacının zaman içerisinde sınırlandırılmış bir veya birkaç 
durumu çoklu kaynaklar içeren veri toplama araçları ile derinlemesine incelediği, durumların ve duruma bağlı temaların tanımlandığ 1 nitel bir araştırma yaklaşımıdır (Creswell, 2007).

\subsection{Araştırma Grubu}

Yapılan bu çalışmada, 13 kız ve 12 erkek olmak üzere toplamda 25 öğrenci yer almıştır. Öğrenciler ortaokul kademesinde 5, 6, 7 ve 8. sınıf öğrencilerinden seçilmiştir. Ayrıca öğrencilerin, eğitim başlamadan önce kendilerine uygulanan anketlerdeki verilerden yararlanılarak üstün/özel yetenekli tanısı olup olmadığı incelenmiş ve öğrenciler daha önce STEM eğitimi alma durumu vb. sorularla araştırmacılar tarafından seçilmişlerdir. Çalışma grubundaki öğrencilerin hiçbiri eğitim öncesinde herhangi bir STEM eğitimi almamışlardır. Ayrıca her öğrencinin üstün/özel yetenekli olduklarına dair raporları bulunmaktadır.

\subsection{Uygulama}

$\mathrm{Bu}$ araştırmanın uygulama aşaması 2 hafta ve 32 saat olarak gerçekleştirilmiştir. Bir ders saati 45 dakika olarak uygulanmıştır. STEM eğitimi ile ilgili 3 alan uzmanının görüşüne başvurulmuştur. Uygulamalarda STEM eğitimi yaklaşımı ile bilgiler, bilimsel yöntem, mühendislik tasarım döngüsü vb. konular öğrencilere öğretilmiştir. $\mathrm{Bu}$ bilgilerin yanı sıra 8 adet etkinlik öğrencilere uygulanmıştır. Öğrenciler her etkinlikte mühendisliğin temel ilkelerini ve problem çözme basamaklarını kullanmışlardır. Her etkinlik sonrasında aktivite değerlendirme formları öğrencilere dağıtılarak öğrencilerin doldurmaları sağlanmıştır. Öğrencilere etkinliğe göre 10-20 dakika arasında süre verilmiştir. Uygulanan 8 etkinlik ile ilgili özet bilgiler aşağıda yer almaktadır:

Marsmallow Challenge: Bu etkinlikte öğrencilerden makarnaları kullanarak bir kule oluşturması beklenmektedir. Öğrenciler gruplar halinde çalışarak makarnaları ve bantları kullanarak en yüksek kuleyi yapmaya çalışmışlardır. Etkinlik sonunda kulenin tepesine bir adet marsmallow konularak kulenin dayanıklılığ 1 test edilmiştir.

Mars Görevi: Öğrencilerin Mars’a gönderilen bir uzay aracını tasarlamaları ve temsili uzay aracını güvenli bir şekilde Mars yüzeyine indirmeleri gerekmektedir. Öğrencilere bu görev için NASA tarafindan Mars'a gönderilen uzay aracının animasyon görüntüleri izletilmiş ancak öğrencilere her hangi bir yönerge verilmemiştir. Öğrenciler bu etkinlikte mühendislik tasarım döngüsünü kullanıp grup halinde tasarımı gerçekleştirmişlerdir. Bu esnada fen bilimleri ve matematik ile ilgili kazanımları elde etmiş, görev sonunda temsili uzay aracı belirli bir yüksekten bırakılarak test edilmiştir.

Güneş sisteminin ölçekli modeli: Bu aktivite ile öğrencilerin güneş sisteminin gerçek boyutlarda (uzaklık ve büyüklük) tasarımını içermektedir. Uygulamaya başlamadan öğrencilere güneş sistemi hakkında videolar gösterilmiştir. Öğrenciler gruplar halinde çalışarak güneş sistemini incelemiş ve gezegenlerin gerçek boyutları ile birbiri ile arasındaki mesafeleri belirlemiştir. Daha sonra çeşitli basit malzemeler ile güneş sistemini ölçekli bir şekilde oluşturmuşlardır.

Köprü tasarımı: Bu etkinlikte öğrencilerin belirli bir ağırlığı taşıyacak bir köprü tasarlamaları beklenmiştir. Öğrencilere çeşitli basit malzemeler verilmiş ve onlardan dünyada yapılmış köprüleri ve özelliklerini araştırmaları istenmiştir. Öğrencilerin yaptığ 1 araştırmadan sonra kendi köprülerini tasarlaması ve kendilerine verilen malzemeleri kullanarak köprülerini oluşturması kendilerinden beklenmiştir. 
Etkinlik sonunda belirli ağırlıklarla öğrencilerin köprülerinin dayanıklıkları test edilmiştir.

Aydınlatma Ürünü Tasarımı: Bu etkinlikte öğrencilerin elektrik devrelerini ve diğer basit malzemeleri kullanarak kendi orijinal aydınlatma ürünlerini tasarlarlamaları hedeflenmiştir. Etkinlikte öğrencilere basit elektrik devreleri verilmiş ve bunları kullanarak basit elektrik devresi kurmaları istenmiştir. Basit elektrik devresinden yola çıkarak aydınlatma ürünleri diğer basit malzemelerle birlikte hazırlanmıştır. Öğrencilerin kendi malzeme taleplerine göre malzeme verilmiştir. Ortaya çıkan ürünlerin çalışıp çalışmadığı test edilmiştir.

Rüzgâr türbini tasarımı: Bu etkinlikte öğrencilerden kendi rüzgâr türbinlerini yapmaları ve çalıştırmaları hedeflenmiştir. Etkinlikte yenilenebilir enerji kaynakları hakkında öğrencilerin araştırma yapmaları ve tartışmaları sağlanmıştır. Öğrenciler gruplar halinde kendilerine verilen ya da kendi talep ettikleri basit malzemeleri kullanarak rüzgâr enerjisinden yararlanmayı sağlayacak bir rüzgâr türbini oluşturmuşlardır. Bu rüzgâr türbinleri rüzgârlı bir ortamda ya da oluşturulan bir rüzgâr ortamında test edilmiştir.

Kaleidoskop Yapımı: Bu etkinlikte öğrencilerden 1şığın kırılmasını ve renklere ayrılmasını sağlayacak bir kaleidoskop tasarlamaları istenmiştir. Etkinlik öncesinde öğrencilere 1şığın kırılması ile ilgili bir video izletilmiştir. Öğrencilere basit malzemeler ve ihtiyaç hissetmeleri durumunda talep ettikleri malzemeler verilerek grup arkadaşlarıyla beraber fikir alışverişi yaparak bir kaleidoskop tasarlamaları sağlanmıştır. Gruplar ilk önce kendi yaptıkları kaleidoskopları denemişlerdir. Daha sonra ise diğer grupların hazırlamış oldukları kaleidoskopları denemişlerdir.

Inovatif ürünler: Bu etkinlikte öğrencilere verilen malzemeler ve kendilerinin talep ettikleri malzemelerle inovatif bir araç tasarlamaları istenmiştir. Öğrenciler gruplar halinde tasarımlarını oluşturmuşlar ve bu tasarımlara göre inovatif araçlarını hazırlamışlardır. Daha sonra ortaya çıkan ürünler öğrenci grupları tarafından sunulmuştur.

\subsection{Veri toplama Araçları ve Analizi}

$\mathrm{Bu}$ araştırmada veri toplama aracı olarak Aktivite Değerlendirme Formları kullanılmıştır. $\mathrm{Bu}$ formda öğrenciler; aktivitelerden neler kazandıklarını, ne tür becerileri elde ettiklerini, bu etkinliklerden elde ettiklerini ilerde nerede ve nasıl kullanabilecekleri, hangi malzemeleri kullandıkları vb. soruları cevaplandırmışlardır. Her aktivitenin sonunda 15 dakikalık sürede öğrenciler aktivite değerlendirme formundaki soruları cevaplandırmışlardır. Uygulanan 8 aktivitenin sonunda öğrenciler tarafindan doldurulan toplam aktivite değerlendirme formu sayısı 315 adettir.

Aktivite değerlendirme formlarındaki sorulardan elde edilen veriler soru bazında betimsel analiz tekniği ile çözümlenmiştir. Betimsel analizde farklı kişilerin aynı soru hakkında farklı düşüncelerinin görüşülenlerden elde edildiği tarzda aktarılır. Betimsel analiz dört aşamadan oluşur (Altunışık ve diğerleri, 2010). Bunlar betimsel analiz için bir çerçeve oluşturma, tematik çerçeveye göre verilerin işlenmesi, bulguların tanımlanması ve bulguların yorumlanmasıdır. Betimsel analiz yapılırken öğrencilerin verdiği her cevap bir kod ile değerlendirilmiştir.

Veri toplama soruları hazırlanırken araştırmacılar dişında üç alan uzmanının görüşüne başvurulmuştur. Glesne ve Peshkin'e göre (1992) nitel araştırmalarda elde edilen veriler nitel araştırmalar konusunda uzman olan kişilerle paylaşılarak dönüt 
alınması araştırmanın güvenirliğini artırmaktadır (Yıldırım, 2010). Toplanan veriler ayrıntılı olarak rapor edilmekte ve araştırmacılar sonuçlara nasıl ulaştıklarını açıklamaktadır. Bu da nitel bir araştırmada geçerliğin önemli ölçütleri arasındadır (Yıldırım \& Şimşek, 2013). İç geçerliğin sağlanabilmesi için araştırmada uzman incelemesi, katılımcı teyidi yapılmış ve inandırıcılığın sağlanabilmesi için elde edilen veri sonuçlarının tutarlılığ 1 değerlendirilmiştir. Nitel araştırmanın güvenirliği bağlamında araştırmacı, araştırma sürecindeki konumunu ve katılımcıların özelliklerini açıklamıştır. Araştırmanın verilerinin güvenirliğini artırmak için veri analizi yapılmadan önce veriler okunarak yanlış anlamalar, konu dışı veriler ayıklanıp veri analiz sürecine dâhil edilmemiştir. Araştırmada iç güvenirliği (tutarlığı) sağlamak için bulgularda doğrudan alıntılara yer verilmiştir.

\section{BULGULAR}

Araştırmada ilk olarak öğrencilere etkinlikten ne öğrendin sorusu yöneltilmiştir. 8 etkinlik sonunda doldurulan toplam 315 adet aktivite değerlendirme formundaki 1. soruya verilen cevaplar betimsel analiz tekniği ile değerlendirilmiştir (Tablo 1). Öğrencilerin verdiği her cevap bir kod ile değerlendirilmiştir.

Tablo 1. Etkinliklerden öğrenilen kazanımlar

\begin{tabular}{lcc}
\hline & f & \% \\
\hline Mühendislik / Mimarlık kazanımları & 134 & 42.5 \\
\hline 21. YY. Becerileri kazanımları & 61 & 19.4 \\
\hline Fen Bilgisi kazanımları & 57 & 18.1 \\
\hline Matematik Bilgisi kazanımları & 48 & 15.2 \\
\hline Malzeme Bilgisi & 15 & 4.8 \\
\hline Toplam & 315 & 100 \\
\hline
\end{tabular}

Tablo 1'e göre öğrencilerin \% 42.5 Mühendislik/Mimarlık kazanımlarını, \% 19.4 oranında 4C (yaratıcılık, iş birliği, eleştirel düşünebilme ve iletişim kurma vb.) 21. YY Becerileri kazanımlarını, \% 18.1 Fen Bilimleri kazanımlarını ve \% 15.2 Matematik kazanımlarını elde ettikleri tespit edilmiştir. Etkinliklerin fen bilimleri ve matematik kazanımları üzerine kurulu olması ve mühendislik becerilerini gerektirmesi öğrencilerin yapılan etkinliğin hedeflerine ulaştıklarını göstermektedir.

1. soruya verilen cevaplardan bazıları aşağıdaki gibidir:

“Bir proje geliştirirken zamanın ve malzeme miktarının önemini öğrendim.

Önce plan yapıp daha sonra denemeler yaparak fikrimi geliştirmeyi

ögrendim." (Öğrenci-16)

“Bu

etkinlikte matematiği (açıları), sürtünme kuvvetinin önemini öğrendim.

(Öğrenci-19)

“Denge merkezinin önemini ve temelin să̆lam olmasının önemini öğrendim." (Ö̆grenci-8)

"Dengeyi korumam gerektiğini düşündüm ve bir sonraki projelerimde bu konuyu değerlendirmem gerekiyor. Ayrıa grup değerlendirmesini ve iletişimin önemini." (Öğrenci-8)

"Rüzgâr türbininin ne kadar yararl, yapımının ne kadar maliyetli ve tehlikeli olduğunu, rüzgâr türbini yaparken simetrinin önemini ve rüzgârl en verimli şekilde kullanmanın yollarını ögrendim." (Öğrenci-7) 
Öğrencilerin görüşlerine göre fen bilimleri ve matematik kazanımları ile mühendisliğin temel becerilerinin öne çıktığı görülmektedir. $\mathrm{Bu}$ durum STEM eğitiminin amacı ile örtüşmektedir. Ayrıca malzemeleri verimli ve etkin kullanma becerisinin de geliştiği söylenebilir.

Araştırmada ikinci olarak öğrencilerin etkinliklerde elde ettiği beceriler sorular sorulmuştur. Elde edilen veriler Tablo 2'de yer almaktadır.

Tablo 2. Öğrencilerin elde ettiği beceriler

\begin{tabular}{lcc}
\hline & f & $\%$ \\
\hline 21. YY. Becerileri & 113 & 43.8 \\
\hline Mühendislik / Mimarlık Yöntemleri & 94 & 36.4 \\
\hline Matematik Bilgisi & 26 & 10.1 \\
\hline Fen Bilgisi & 25 & 9.7 \\
\hline Toplam & 258 & 100 \\
\hline
\end{tabular}

Tablo 2’ye göre öğrencilerin, \% 43.8 oranında 21.YY. Becerileri, \% 36.4 Mühendislik/Mimarlık Becerileri, \% 10.1 Matematik Becerileri ve \% 9.7 Fen Bilimleri becerileri kazandıkları yönünde cevaplandırılmıştır. Öğrencilerin iletişim kurma, işbirliği yapma, yaratıcılık, eleştirel düşünme, problem çözme vb. 21. YY. becerilerini elde ettikleri görülmektedir. 21. YY. becerilerini mühendislik becerileri takip etmektedir.

2. soruya verilen cevaplardan bazıları aşağıdaki gibidir:

“Olasılıkları düşünerek matematik kullandık.” (Öğrenci-19)

"Grup olarak ortak çalışma becerisi, dengede durabilen bina veya ev modellerini anlama ve geliştirme becerisi kazandiğımı düşünüyorum. ” (Öğrenci-16)

"Çabuk düşünme ve hızlı hareket etme becerilerini kazandığımı düşünüyorum.” (Öğrenci-10)

"El yeteneği, daha fazla düşünce gücü, zorluklarla başa çıkma yeteneği." (Öğrenci-17)

“Dikkatimi geliştirdim. Aynı zamanda el becerimi geliştirdim.” (Öğrenci-21)

"Bu etkinlik ile beyin firtınası yapma becerisini ve el becerisini kazandiğımı düşünüyorum.” (Öğrenci-25)

"Dengeyi korumam gerektiğini düşündüm ve bir sonraki projelerimde bu konuyu değerlendirmem gerekiyor. Ayrica grup değerlendirmesini ve iletişimin önemini. " (Öğrenci-8)

Yukarıda yer alan örnek öğrenci görüşleri 21. YY. becerilerini ve mühendislik becerilerini öne çıkarmaktadır. STEM eğitiminin en önemli hedeflerinden ikisi bu becerileri elde etmektir.

Araştırmada üçüncü olarak öğrencilerin öğrendiklerini gelecekte nasıl kullanacaklarına dair sorular sorulmuştur. Elde edilen veriler Tablo 3'de yer almaktadir.

Tablo 3. Öğrencilerin öğrendiklerini gelecekte kullanma durumları 


\begin{tabular}{lcc}
\hline Mühendislik / Mimarlık & 87 & 52.1 \\
\hline Ürün Tasarlama & 47 & 28.1 \\
\hline 21. YY. Becerileri & 18 & 10.8 \\
\hline Astronomi & 9 & 5.4 \\
\hline Matematik & 5 & 3 \\
\hline Fen Bilimleri & 1 & 0.6 \\
\hline Toplam & 167 & 100 \\
\hline
\end{tabular}

Tablo 3'e göre öğrencilerin öğrendiklerini \% 52.1 Mühendislik / Mimarlık alanlarında, \% 28.1 Ürün tasarlamada, \% 10.8 problem çözme gibi 21. YY. becerilerinin kullanıldığ 1 ortamlarda kullanabilecekleri tespit edilmiştir. Öğrencilerin genel olarak STEM'in önemli disiplinlerinden birisi olan mühendislik konusunda bilgi sahibi oldukları, ürün tasarlama becerilerini elde ettikleri ve 21. YY. becerilerine sahip oldukları anlaşılmaktadır.

3. soruya verilen cevaplardan bazıları aşağıdaki gibidir:

“Gelecekte mühendis olursam geçirgenliği ayarlarken kullanabilirim." (Öğrenci-25)

“Mühendislikte ve teknolojide. ”(Öğrenci-20)

"Gelecekte ĕger depremle ilgili bir kurumda çalışırsam iyi bir tasarım çıkarabilirim."

(Ögrenci-12)

"Gelecekte buradan ögrendiklerimde mimarlık konusunda veya daha yakın gelecekte proje maketi yaparken kullanabilirim.” (Öğrenci-15)

"Karşıma çıkan problemle kısa sürede çözüm bulabilirim. Daha sonra katılacağım proje yarışmalarında değişik fikirler üretme konusunda bir etkinlikten faydalanabilirim." (Öğrenci-16)

"Rüzgâr türbininin bilgisayar tasarımını yaparsam öğrendiğim bilgileri kullanırım.” (Öğrenci-3)

Öğrenci görüşleri incelendiğinde elde edilen bilgilerin mühendislik alanlarında ve ürün tasarlamada kullanılabileceği görülmektedir. Bu durum STEM eğitiminin amacına ulaştığını göstermektedir.

Araştırmada dördüncü olarak öğrencilerin malzemeleri değerlendirmelerini içeren sorular sorulmuştur. Elde edilen veriler Tablo 4'de yer almaktadır.

Tablo 4. Öğrencilerin malzeme değerlendirmeleri

\begin{tabular}{lcc}
\hline & f & \% \\
\hline Bant & 45 & 21.4 \\
\hline Makarna & 44 & 21 \\
\hline Pipet & 18 & 8.6 \\
\hline Ayna & 16 & 7.6 \\
\hline Gezeglang & 16 & 7.6 \\
\hline
\end{tabular}




\begin{tabular}{lcc}
\hline Bağlantı Kablosu & 12 & 5.7 \\
\hline Ampul & 11 & 5.2 \\
\hline Pil & 9 & 4.3 \\
\hline Diğerleri & 27 & 12.8 \\
\hline Toplam & $\mathbf{2 1 0}$ & $\mathbf{1 0 0}$ \\
\hline
\end{tabular}

Tablo 4'e göre öğrencilerin \% 21.4 oranında bant, \% 21 oranında makarna, \% 8.6 oranında pipet gibi malzemelerin daha çok kullanıldığ ve etkinlikler için önemli olduğu görülmektedir. Bu malzemeler hem araştırmacılar tarafından öğrencilere verilmiş hem de öğrenciler kendileri bu malzemeleri talep etmişlerdir. Tasarlama esnasında malzemelerin birbirine tutturulması önem taşımaktadır. Bundan dolayı bant kullanımının ön planda olduğu söylenebilir.

4. soruya verilen cevaplardan bazıları aşağıdaki gibidir:

"Pipetler. Çünkü hangi yöne düşerse düşü̈n tasarım, pipetlerden dolayı kırllmayabilir. Çünkü pipetler bir kafes görevi görüyor.” (Öğrenci-8)

"Bence makarna çubuğu en önemli malzemeydi. Çünkü en fazla maketimizde onun katkısı oldu.” (Öğrenci-23)

"Bant, çünkü bütün yapıyı ayakta tutan mimari bant ile oluşturuldu." (Öğrenci-25)

“Kablo çünkü o olmasa elektrik iletilemezdi.” (Öğrenci-13)

“Abeslang- havanın akımını yakalamak için gerekliydi.” (Öğrenci-17)

"Bence aynaydl. Çünkü aynanın lşı̆̆ yansıtmasından faydalanarak kaleydeskobu elde ettik.” (Öğrenci-16)

"Bence banttı çünkü bant aslında deneyde güneşin çekimi yerine görev alıyordu yani bant olmasa gezegenler yerinde durmazdl." (Öğrenci-10)

Öğrenci görüşlerine göre pipetlerin esneklik sağlaması, makarnaların birleştirilerek dayanıklı bir malzeme üretilmesi, bant kullanılarak malzemelerin birbirine tutturulması ve bantların tasarımın ayakta durmasını sağlaması önemli olmasını sağlamıştır.

Araştırmada beşinci olarak öğrencilerin etkinliklerde ek olarak kullanmak istedikleri malzemeler sorulmuştur. Elde edilen veriler Tablo 5'de yer almaktadır.

Tablo 5. Öğrencilerin ek olarak kullanmak istedikleri malzemeler

\begin{tabular}{lcc}
\hline & f & \% \\
\hline Diğer malzemeler & 120 & 57.1 \\
\hline Farklı tür yapıştırıcı & 54 & 25.7 \\
\hline Pamuk & 15 & 7.1 \\
\hline Marshmallow & 11 & 5.2 \\
\hline Tahta & 10 & 4.8 \\
\hline Toplam & $\mathbf{2 1 0}$ & $\mathbf{1 0 0}$ \\
\hline
\end{tabular}

Tablo 5'e göre öğrenciler ek olarak hangi malzemeyi kullanmak istersiniz sorusuna çok çeşitli cevaplar verilmiştir. Bundan dolayı çok küçük oranlarda temsil edilen malzemeler diğer kodu altında toplanmıştır. Ek olarak kullanılmak istenen malzemelerin oranları ise şöyledir: \% 57.1 oranında diğer, \% 25.7 oranında farklı tür yapıştırıcı, \% 7.1 oranında pamuktur. Diğer malzemeler kodunun yüksek çıkması ögrencilerin farklı tasarlama düşüncelerine sahip olması ve bundan dolayı farklı 
malzemeleri talep etmesinden kaynaklanmaktadır. Bu durum da yaratıcı düşünmeyi ön plana çıkarmaktadır.

5. soruya verilen cevaplardan bazıları aşağıdaki gibidir:

“Tutkal, bantlamak çok zordu.” (Öğrenci-7)

"Marshmallow çünkü kolay batarak kolay ayakta tutardl." (Öğrenci-25)

"Pamuk ve poşet. Poşet inerken içi ne hava dolacak ve paraşüt görevini görecek. Pamuk da yumuşak inişi sağlayacak.” (Öğrenci-3)

"Kartonun yerine tahta kullanmak isterdim. Böylece aynalar daha să̆lam etrafina sarlmış olacaktı ve düşmeyecekti.” (Öğrenci-10)

"Makarnadan daha sağlam ve daha esnek malzemeler kullanmak isterdim. Örneğin; lastik bükülebilir tel, karton, köpük... Çünkü bu tarz malzemeler le daha dayanıklı bir köprü oluşturabilirdim." (Öğrenci-16)

Yapıştırıcılar tasarlamada en çok kullanılan malzemelerden birisi olarak karşımıza çıkmaktadır. Bundan dolayı öğrenciler farklı türde ve dayanıklı yapıştırıcı talep etmiştir. Öğrencilere yönerge verilmediği için yaratıcılıkları sınırlanmamış ve öğrenciler de farklı malzemeler kullanmak istediklerini belirtmişlerdir.

Araştırmada altıncı olarak öğrencilerin tasarımı geliştirmek için neler yapacağ hakkında sorular sorulmuştur. Elde edilen veriler Tablo 6'da yer almaktadır.

Tablo 6. Öğrencilerin yeniden tasarlama hakkında görüşleri

\begin{tabular}{lcc}
\hline & $\mathbf{f}$ & $\mathbf{\%}$ \\
\hline Prototip değișikliği & 142 & 70.6 \\
\hline Diğer & 24 & 11.9 \\
\hline Matematiksel hesaplama & 18 & 9 \\
\hline Malzemelerin verimli kullanımı & 11 & 5.5 \\
\hline İletişim (iș birliği) & 6 & 3 \\
\hline Toplam & $\mathbf{2 0 1}$ & $\mathbf{1 0 0}$ \\
\hline
\end{tabular}

Tablo 6'ya göre öğrenciler elde ettikleri tecrübelere önceden sahip olsalardı bu tecrübeyi $\% 70.6$ oranında prototip değişikliği, $\% 9$ oranında matematiksel hesaplama ve $\% 5,5$ oranında malzemelerin verimli kullanmak için kullanacaklarını belirtmişlerdir. STEM eğitiminde öğrenciler tecrübe edindikçe mühendislik tasarım döngüsünün en önemli adımlarından birisi olan prototip oluşturma ve test etmeyi daha fazla kullanacaklardır. Ayrıca matematiği daha iyi ve malzemeleri daha verimli kullanacaklardır.

6. soruya verilen cevaplardan bazıları aşağıdaki gibidir:

"Boncukların renklerini daha açık seçerdim. Böylece ışık daha kolay girebilirdi."(Öğrenci-12)

"Tabi ki de rüzgâr akımını doğru kullanmak için daha aerodinamik bir şekilde abeslanglart yerleştirirdik.” (Öğrenci-15)

"Kablolar benim için çok sorun oldu. Bununla ilgili birkaç şey düzenleyebilirdim belki.”(Öğrenci-7)

"Herkesin fikrini değerlendirirdik ve sorumluluklarımızın farkında olurduk." (Ö̆grenci-8) 
"Ü̧̧gen yerine küp kullanırdım. Yüzeyi ve temeli daha sağlam olabilirdi." (Öğrenci-10)

"Hiçbir şey çünkü güzel oldu." (Ö̈̆renci-21)

Öğrencilerin görüşleri incelendiğinde öğrencilerin tecrübe edindikleri görülmektedir. $\mathrm{Bu}$ tecrübe onların daha sonraki etkinliklerde başarılı olmasının ve daha iyi ürünler ortaya koymalarını sağlayacaktır.

Araştırmada yedinci olarak öğrencilerin etkinliklerden hoşlanıp hoşlanmadıkları sorulmuştur. Elde edilen veriler Tablo 7'de yer almaktadır.

Tablo 7. Öğrencilerin etkinliklere yönelik tutumları (Bu etkinlik eğlenceli miydi? En çok ne hoşuna gitti?)

\begin{tabular}{lcc}
\hline & f & $\boldsymbol{\%}$ \\
\hline Evet & 167 & 85.6 \\
\hline Hayır & 28 & 14.4 \\
\hline Toplam & $\mathbf{1 9 5}$ & $\mathbf{1 0 0}$ \\
\hline
\end{tabular}

Tablo 7'ye göre öğrencilerin etkinlikleri \% 85.6 gibi oldukça yüksek bir oranda eğlenceli buldukları, \%14.4 oranında ise eğlenceli bulmadıklarını tespit edilmiştir. Genel olarak değerlendirildiğinde yapılan etkinliklerin büyük oranda eğlenceli bulunduğu söylenebilir. STEM eğitimi yaklaşımı bilgilerin teorik öğretiminden ziyade elde edilen bilgilerin kullanılarak tasarlamayı ve ürüne dönüştürmeyi içermesi öğrencilerin motivasyonların artırmaktadır.

7. soruya verilen cevaplardan bazıları aşağıdaki gibidir:

"Evet, en çok grubumdaki arkadaşlarımla bu konuda, tasarımı tasarlarken sohbetimiz ve yumurtayı atış süreci zevkliydi." (Öğrenci-8)

"Çok eğlenceliydi, en çok hoşuma giden takım çalışmasıydl." (Öğrenci-25)

"Çok fazla eğlenmedim. Ancak en sonda test ederken heyecanlanmış sonunda kazanınca daha doğrusu çalışmamız başarılı olunca çok sevinmiştim.” (Öğrenci-7)

"Evet. En çok rüzgâr tribünümüzün dönmediğini gördüğüm ve eksiklerimizi gördüğ̈̈müz zaman hoşuma gitti." (Öğrenci-19)

"Evet, en çok uzaklıkları hesaplarken eğlendim." (Öğrenci-10)

"Hayır, eğlenceli değildi çünkü kafamdakini gerçeğe çeviremedik." (Öğrenci15)

Öğrencilerin tasarım sürecini zevkli buldukları, takım çalışmasından hoşlandıkları, tasarımlarının ürüne dönüşmesinden mutlu oldukları ancak tasarladıklarını hayata geçiremeyenlerin ve zorluk yaşayanların hoşnut olmadıkları tespit edilmiştir.

Araştırmada sekizinci olarak öğrencilerin eğitim öncesinde ve sonrasında kariyer yönelimleri incelenmiştir. Elde edilen veriler Tablo 8'de yer almaktadır.

Tablo 8. Etkinliklerin öğrencilerin kariyer yönelimlerine etkisi

\begin{tabular}{lcccc}
\hline & \multicolumn{3}{c}{ Eğitim Öncesi } & \multicolumn{2}{c}{ Eğitim Sonrası } \\
\cline { 2 - 5 } & $\mathbf{f}$ & $\boldsymbol{\%}$ & $\mathbf{f}$ & $\boldsymbol{\%}$ \\
\hline STEM Dışı Alanlar (Tıp vb.) & 13 & 52 & 9 & 36 \\
\hline
\end{tabular}




\begin{tabular}{lcccc}
\hline STEM Alanları (mühendislik, temel bilimler vb.) & 12 & 48 & 16 & 64 \\
\hline Toplam & $\mathbf{2 5}$ & $\mathbf{1 0 0}$ & $\mathbf{2 5}$ & $\mathbf{1 0 0}$ \\
\hline
\end{tabular}

Tablo 8'e göre öğrenciler STEM eğitimi öncesi \% 52 oranında STEM dış1 alanlarda meslek sahibi olmak isterlerken, eğitim sonrası bu oran \% 36'ya düşmüştür. Eğitim öncesinde STEM alanlarında meslek sahibi olmak isteyenlerin oranı $\% 48$ 'den \% 64'e yükselmiştir. Bu durum STEM eğitiminin öğrencilerin STEM alanlarına yönlendirilmesinde etkili olduğu şeklinde yorumlanabilir.

8. soruya verilen cevaplardan bazıları aşağıdaki gibidir:

“Mühendisliği. Çünkü bir şeyler oluşturmak hoşuma gitti.” (Öğrenci-25)

"Bana çok az şeyden çok güzel şeyler yapılacağını öğrettiği için endüstri tasarımcısı olmak isteğim arttı." (Öğrenci-10)

“Evet, oldu çünkü tasarım bana mimarlık alanında fikir săgladı.” (Öğrenci-1)

"Hayır olmadı. Çünkü bu alana yönelik bir meslek sahibi olmak istemiyorum." (Ögrenci-16)

"Belki, seçeceğim meslekte öğrendiklerimi kullanmama yardım eder." (Öğrenci-8)

"Hayır olmadı. Ama bu cevap etkinliğin yararlı olmadĭ̆ anlamına gelmez. Yine de bu alana yönelik bir meslek tercihi yapmak istemiyorum.” (Öğrenci-16)

"Evet, ĕger bir iş yeri sahibi olursam çalışan seçerken daha dikkatli olacă̆ım.”(Öğrenci-21)

Öğrencilerin verdikleri cevaplar incelendiğinde, STEM alanlarında meslek tercih etmek isteyenlerin bir şeyler oluşturmak ve tasarlamak istedikleri için bu alanları tercih ettikleri söylenebilir. Bu durum STEM eğitimi yaklaşımının ana hedefleri ile örtüşmektedir.

\section{TARTIŞMA ve SONUÇ}

Üstün/Özel yetenekli öğrenciler için düzenlenen STEM eğitimi sonucunda öğrencilerin çoğunlukla mühendislik ve mimarlık kazanımları elde ettiği, İngilizcede 4C denilen (yaratıcılık, iş birliğii, eleştirel düşünebilme ve iletişim kurma) gibi 21. YY. becerileri kazandığı, öğrencilerin etkinliklerden elde ettikleri kazanımları mühendislik ve mimarlık çalışmalarında ve ürün oluşturmada kullanabilecekleri, öğrencilerin farklı bakış açılarıyla yapılan aktiviteleri farklı şekillerde ve farklı malzemelerle yeniden tasarlayabilecekleri, tasarımı geliştirmek için başta hazırladıkları prototipleri değiştirebilecekleri, öğrencilerin aktiviteleri eğlenceli bulduğu ve motivasyonlarının yükseldiği ortaya çıkmıştır. Kim, Roh ve Cho (2016) üstün/özel yetenekli öğrencilerin bütünleşik bir öğretim ile matematik ve fen kavramlarını ayrı düşünmediklerini ve onların doğru çözüm süreçleri tasarladıklarını ayrıca problemleri yaratıcı bir şekilde çözdüklerini öne sürmektedir. Bu çalışmada da aynı sonuçlara ulaşılmıştır. Eğitime katılan öğrencilerin bu dersleri hem uygulamalı hem de mühendislik ve teknoloji ile entegre bir şekilde görmeleri onların bu alanlara olan bakış açılarını da değiştirmiştir. Bilgili (2000)'e göre, üstün/özel yetenekli bireylerin eğitimi bilimsel, teknolojik araştırma ve geliştirme çalışmaları açısından büyük önem arz etmektedir. 
Etkinliklerin fen bilimleri ve matematik kazanımları üzerine kurulu olması ve mühendislik becerilerini gerektirmesi öğrencilerin yapılan etkinliğin hedeflerine ulaştıklarını göstermektedir. Apodoe, Reynolds, Ellefson ve Schunn (2008) çalışmaları sonucunda, tasarım bazlı öğrenme yönteminin kimya dersindeki zorlu temel kavramları öğretmede etkili olabileceğini ve mühendislik konusunda farkındalığı arttırdığı sonucuna varmışlardır. Öğrencilerin bu tarz etkinlikler sonrasında matematiksel işlemleri ürün oluşturma aşamasına entegre etme becerilerinin ve malzemeleri verimli kullanma becerilerinin arttığ1 sonucuna varılmıştır. Naizer, Hawthorne ve Henley (2014), STEM Yaz Kampı'na katılan ortaokul öğrencilerinin matematik bilimi, problem çözme ve teknoloji alanında ilgilerinin ve bu alanlarda kendilerine olan özgüvenlerinin arttığı sonucuna varmışlardır.

$\mathrm{Bu}$ araştırmada olduğu gibi Şahin, Ayar ve Adıgüzel (2014), STEM etkinliklerinin öğrencilerin STEM'e yönelik ilgilerini arttırdığını, yeteneklerini geliştirdiğini; Yamak, Bulut ve Dündar (2014) ise öğrencilerin fen bilimlerine karşı tutumlarını ve bilimsel süreç becerilerini geliştirdiğini belirtmektedir. Bu araştırmada da öğrencilerin mühendislik tasarım becerilerinin oldukça geliştiği söylenebilir. Baran, Bilici, Mesutoğlu ve Ocak'da (2015) 6. sınıf öğrencileri için yaptıkları STEM etkinlikleri ile öğrencilerin mühendislik tasarım süreçlerini geliştirdiğini belirtmiştir. Öğrencilerin ortaya yeni ve özgün ürünler ortaya çıkarabilmesi, eğitimin temelinde not kaygısı olmaması ve yaratıcılıklarını kullanma özgürlügüne sahip olmaları ile açıklanabilir.

Eğitim öncesinde toplanan verilerde öğrencilerin büyük çoğunluğunun STEM dışı alanlara ve özellikle Tıp Fakültelerine yönelmek istedikleri sonucuna varılmıştır. Öğrencilerin STEM alanlarına yönelik meslek eğilimlerinin eğitim sonrasında artış gösterdiği, STEM dışı alanlarda meslek seçimi eğiliminin azaldığı görülmektedir. Akgündüz (2016) yaptığı ÖSYM verileri ile yaptığı araştırmada ilk binde yer alan öğrencilerin daha çok STEM dışı alanlara yöneldiğini belirtmektedir. Eğitimden önce STEM alanı mesleklerini tercih edecek öğrencilerin eğitim sonunda tercihleri değişmezken, Tıp Fakültelerine devam etmek isteyen öğrencilerin STEM alanlarına yöneldiği tespit edilmiştir. Bu durum STEM eğitiminin ana hedeflerine ulaşıldığını göstermektedir. Ancak üstün/özel yetenekli öğrencilerin STEM ile ilgili kazanımlara hazır bulunuşluklarının yüksek olması STEM alanlarında meslek seçimlerinde çok etkili olmamaktadır. Gencer (2015) 7. sınıf öğrencilerine uyguladığı STEM etkinliğinin öğrencilerde fen bilimleri alanında kariyer bilinci geliştirmeye yardımcı olacağını, bu alana iliş̧in bilgi ve becerilerinin gelişeceğini, alana yönelik tutumlarının olumlu yönde olmasına yardımcı olacağını ifade etmiştir. Guzey, Harwell ve Moore (2014) yaptıkları çalışmada STEM odaklı eğitim veren okulların, öğrenciler üzerinde STEM ve STEM kariyer alanlarına dair tutumlarında olumlu gelişmeler ortaya çıkmasını sağlamıştır. Okullarda STEM eğitimi uygulamalarının artması öğrencilerin STEM alanlarına yönlendirilmesini sağlayabilir.

STEM eğitimi tüm öğrenciler için en önemli yaklaşımlardan birisidir. Üstün/özel yetenekliler gibi bilişsel kapasitesi yüksek olanların ve eğilimi olanların STEM eğitimi alması bu yeteneklerinin olumlu yönde değişmesini sağlayabilir. Bu çalışmada mühendislik ağırlıklı bir STEM eğitimi gerçekleştirilmiştir. Başka araştırmalarda bazı disiplinlerin ağırlıkları değiştirilerek STEM eğitimi uygulamaları gerçekleştirilebilir. Etkinliklerin sayısı ve çeşitlendirilmesi sağlanabilir. Uygulamaların süresi artırılabilir ve bir dönem boyunca uygulanabilir. Bu araştırma 
üstün/özel yetenek tanısı konulmuş ortaokul düzeyindeki öğrenciler, öğrencilerin görüşleri ve uygulanan etkinliklerle sınırlıdır. 


\section{KAYNAKLAR}

Achieve. (2012). Next generation science standarts. http://www.achieve.org/nextgeneration-science-standards.

Akarsu, F. (2001). Üstün yetenekli çocuklar. Ankara: Eduser Yayınları.

Akgündüz, D. (2016). A research about the placement of the top thousand students in STEM fields in Turkey between 2000 and 2014. EURASIA Journal of Mathematics, Science and Technology Education, 12(5), 1365-1377

Akgündüz, D., Aydeniz, M., Çakmakçı, G., Çavaş, B., Çorlu, M. S., Öner, T. \& Özdemir, S. (2015a). STEM eğitimi Türkiye raporu: Günün modası mı yoksa gereksinim mi? [A report on STEM Education in Turkey: A provisional agenda or a necessity?][White Paper]. İstanbul Aydın Üniversitesi: STEM Merkezi ve Eğitim Fakültesi. http://www.aydin.edu.tr/belgeler/IAU-STEM-Egitimi-Turkiye-Raporu2015.pdf

Akgündüz, D., Ertepınar, H., Ger, A. M., Kaplan Sayı, A. \& Türk, Z. (2015b). STEM eğitimi çalıştay raporu: Türkiye STEM eğitimi üzerine kapsamlı bir değerlendirme. İstanbul Aydın Üniversitesi: STEM Merkezi ve Eğitim Fakültesi.

http://etkinlik.aydin.edu.tr/dosyalar/IAU_STEM_Egitimi_Calistay_Raporu 2015.pdf

Altunışık, R., Çoşkun, R., Yıldırım, E. ve Bayraktaroğlu, S. (2010). Sosyal bilimlerde araştırma yöntemleri. 6. Bask1, Sakarya: Sakarya Kitabevi

Apedoe, X. S., Reynolds, B., Ellefson, M. R., \& Schunn, C. D. (2008). Bringing engineering design into high school science classrooms: The heating/cooling unit. Journal of Science Education and Technology, 17(5), 454-465.

Bakioğlu, A. ve Levent, A. F. (2013). Üstün yeteneklilerin eğitiminde Türkiye için öneriler. Journal of Gifted Education Research, 1, 31-44

Baran, E , Canbazoglu Bilici, S , Mesutoglu, C , Ocak, C . (2016). Moving STEM beyond schools: Students' perceptions about an out-of-school STEM education program. International Journal of Education in Mathematics, Science and Technology, 4(1), 9-19. DOI: 10.18404/ijemst.71338Bilgili, A. E. (2000). Üstün yetenekli çocukların eğitimi sorunu - Sosyal sorumluluk yaklaşımı. M. Ü. Atatürk Ĕğitim Fakültesi Eğitim Bilimleri Dergisi, (12), 59-74.

Bybee, R. W. (2010). What is STEM education? Science, 329(5995), 996-996.

Çavaş, B., Bulut, Ç., Holbrook, J., \& Rannikmae, M. (2013). Fen eğitimine mühendislik odaklı bir yaklaşım: ENGINEER projesi ve uygulamaları [An engineering-focused approach to science education: ENGINEER projects and applications], Fen Bilimleri Öğretimi Dergisi, 1(1), 12-22.

Creswell, J. W. (2007). Qualitative inquiry and research design: Choosing among five approaches (2nd ed.). Thousand Oaks, CA: Sage.

EGEÇEM. (2017). Fen-teknoloji mühendislik-matematik (FETEMM) etkinlikleriyle bilimi öğreniyorum programı (5. 6. ve 7. sinıf). http://egitim.ege.edu.tr/ egecem/?page_id=509

Gencer, A. S. (2015). Fen eğitiminde bilim ve mühendislik uygulaması: Fırıldak etkinliği. Araştırma Temelli Etkinlik Dergisi, 5(1), 1-19. 
Guzey, S. S., Harwell, M., Moore, T. (2014). Development of an instrument to assess attitudes toward science, technology, engineering, and mathematics (STEM). School Science and Mathematics, 114(6), 271-279.

Gökdere, M. \& Çepni, S. (2004). Üstün yetenekli öğrencilerin fen öğretmenlerinin hizmet içi ihtiyaçlarının değerlendirilmesine yönelik bir çalışma; Bilim sanat merkezi örneklemi. Gazi Ĕ̌itim Fakültesi Dergisi, 24(2), 1-14

Haciömeroğlu G., Kiliç A.S. (2016). Entegre FeTeMM öğretimi yönelim ölçeği Türkçe formunun geçerlik ve güvenirlik çalışması. Eğitimde Kuram ve Uygulama, 12(3), 654-669.

Kim, M.K., Roh, I.S., Cho, M.K. (2016). Creativity of gifted students in an integrated math-science instruction. Thinking Skills and Creativity 19 (2016) 38-48

Naizer G., Hawthorne M. J., Henley T. B. (2014). Narrowing the gender gap: enduring changes in middle school students' attitude toward math, science and technology. Journal of STEM Education: Innovations and Research, 15(3), 29-34.

Smutny, J. F. \& von Fremd, S. E. (2004). Differentiating for the young child: Teaching strategies across the content areas $(K-3)$. Thousand Oaks, CA: Corwin Press.

STEM OKULU. (2017). STEM Okulu. www.stemokulu.com.

Şahin, A., Ayar, M.C. \& Adıgüzel, T. (2014). Fen, teknoloji, mühendislik ve matematik içerikli okul sonrası etkinlikler ve öğrenciler üzerindeki etkileri. Educational Sciences: Theory ve Practice, 14(1), 297-322.

Tyler-Wood T. L., Mortenson M., Putney D., Cass M. A. (2000). An effective mathematics and science curriculum option for secondary gifted education. Roeper Review, 22, 266-270.

Tomlinson, C. (2000). Reconcilable differences? Standards-based teaching and differentiation. Educational Leadership, 58(4), 6-11.

VanTassel-Baska, J. \& Stambaugh, T. (2006) Comprehensive curriculum for the gifted. Boston, MA: Pearson.

Yamak, H., Bulut, N., \& Dündar, S. (2014). 5. Sınıf öğrencilerinin bilimsel süreç becerileri ile fene karşı tutumlarına FeTeMM etkinliklerinin etkisi. Gazi Üniversitesi Gazi Ĕ̌itim Fakültesi Dergisi, 34(2), 249-265.

Yıldırım, K. (2010). Nitel araştırmalarda niteliği artırma. Ilköğretim Online, 9 (1), 79- 92.

Yıldırım, A. \& Şimşek, H. (2013). Sosyal bilimlerde nitel araştırma yöntemleri. Ankara: Seçkin. 


\section{EXTENDED ABSTRACT / UZUN ÖZ}

\section{Evaluation of Gifted/Talented Students' Out-of-School STEM Education}

New approaches are needed in order that students have skills, like creativity, critical thinking, communicating, cooperating, problem solving and having technology literacy (P21, 2016), which are called 21st Century skills, and make product-focused studies. In the $21 \mathrm{st}$ century, STEM education is the most important of these approaches. STEM, which is a concept originated in the United States, means combining the knowledge of science and mathematics with practices and applications of engineering and technology (Akgunduz et al, 2015a, 2015b; Akgunduz, 2016). A properly applied STEM education develops the features of the students such as understanding the working principles of tools-equipment and using technology effectively (Bybee, 2010). In addition, the students' knowledge levels for STEM fields being developed results in an improvement of interest and learning for these areas as well as being important in terms of their choice of profession which they will make in the future (Becker and Park, 2011; Akgunduz et al, 2015a; Hacıömeroğlu and K1lıç, 2016).

STEM education can be applied to all students, however, it has been detected that studies on application of them on gifted/talented students are insufficient. The present study has been done in order to evaluate the achievements the students have gained with the STEM education made for gifted/talented students.

In this research, case study model as a type of the quantitative research method was employed. The study was carried out with the participation of 25 students in total, 12 boys and 13 girls who were distinguished as gifted/talented and had not taken a STEM education before the study. The students were selected by researchers from among the 5th, 6th, 7th, and 8th grade students studying in the secondary school based on their desire to take part in the study.

The application part of this study was realized as 32 hours in 2 weeks. During the applications, the information and the subjects such as scientific methods, engineering-designing cycle etc. were taught to students with the STEM education approach. In addition to this information, 8 activities were applied to the students. In each activity, the students used the basic principles of engineering and problem solving stages. After each activity, activity assessment forms were distributed to the students to fill them out.

In the activity assessment form, there were questions such as what the students had learnt, which skills they had gained, and how they would use what they had learnt from the activity and so on. In each activity that was made, the engineering design period was monitored, and after the activity, it was ensured that the students filled the activity forms. The qualitative data obtained was evaluated by using descriptive analysis technique.

It was detected that the students obtained $42.5 \%$ of Engineering/architecture gaining, $19.4 \%$ of $4 \mathrm{C}$ (creativity, cooperation, critical thinking and communication), the 21 st Century Skills, $18.1 \%$ of Science achievements and $15.2 \%$ of Mathematics achievements from these applications made. The fact that the activities were based on science and mathematics achievement and that they required engineering skills indicate that the students reached the goals of the activities made.

With STEM education, it was detected that the students gained 21st Century Skills at the rate of $43.8 \%$, Engineering/Architecture talents at the rate of $36.4 \%$, Mathematics Skills at the rate of $10.1 \%$ and Science skills at the rate of $9.7 \%$. It is seen that the students have gained the 21 st Century Skills such as communication, cooperation, creativity, critical thinking and problem solving etc. 21st Century Skills are followed by engineering skills

The students stated that they can use $52.1 \%$ of what they learned from the STEM education within Engineering/ Architecture areas, 28.1\% within Product Designing, $10.8 \%$ within problem solving etc.., in areas where 21 st Century skills are used. It is understood that the students generally have gained information about engineering, which was one of the important disciplines of STEM, they gained product designing skills, and 21st Century skills. 
As a result of the evaluations of the materials that the students used in the activities, it was seen that materials such as $21.4 \%$ tapes, $21 \%$ pasta, $8.6 \%$ pipette were used more, and were important for the activities. These materials were either given to the students by the researchers, or the students requested these materials. During the designing, attaching the materials to one another is also important. Therefore, it can be said that tape usage is in the fore front.

Owing to the fact that the students gave various answers to the question "which additional material they would want to use" the materials which were represented with very little ratios were gathered under the other code. The ratios of the materials which were requested to be used are as follows; $57.1 \%$ others, $25.7 \%$ different type of adhesives, $7.1 \%$ cotton. The fact that the code of the other materials turned out to be high arises from the fact that the students have different designing thoughts, hence, they required different materials. This situation brings creative thinking into forefront.

The students indicated that if they had had these experiences before they would have used this experience for prototype change at the rate of $70.6 \%$, for mathematical calculations at the rate of $9 \%$, for productive usage of materials at the rate of $\% 5.5$. As students gained more experiences during STEM education, they will use prototype generation and testing, which is one of the most important steps of engineering designing cycle more frequently. What is more, they will use mathematics better, and materials more productively.

It was detected that the students found STEM education entertaining at the rate of $85.6 \%$, which is quite a high ratio, and $14.4 \%$ reported it as non-entertaining. When evaluated generally, it can be said that the activities made are found entertaining in a high ratio. The fact that the STEM education approach contains designing and converting to new products by using the information obtained rather than only theoretical education increases the motivation of the students.

While $52 \%$ of the students wanted to get occupations other than the occupations under STEM's area before the STEM education, this ratio decreased to $36 \%$ after these applications. The rate of those who wanted to have professions in the STEM areas increased from $48 \%$ to $64 \%$ after the applications. This can be commented as STEM education were effective in directing the students to STEM areas.

As a result of the STEM education organized for gifted/talented students, it appeared that students obtained engineering and architecture achievements the most and gained 21st Century skills (creativity, collaboration, critical thinking and communication) which are called 4C. Moreover, they were able to use the achievements they obtained after the applications related to engineering and architecture studies and creating products. They demonstrated an ability to re-design the activities which were made with different perspectives, in different shapes with different materials. They also showed an ability to change the first prototypes they produced at the start in order to develop the design. They found further the activities as entertaining and their motivations were boosted. 